\title{
South American dust signature in geological archives of the Southern Hemisphere
}

Stefania Gili and Diego M. Gaiero

\begin{abstract}
Patagonian dust is the darling of researchers of paleoclimatic variability of southern South America. However, new chemical data from yet unexplored dust source areas allows for deeper investigation of the geological archives in the
\end{abstract} region.

In present-day southern South America (SSA) the major dust source areas are located in a continuous N-S band of arid and semi-arid terrains extending from the coastal regions of Peru to Patagonia. Three main persistent source areas stand out: Patagonia, CentralWestern Argentina (CWA) and the Puna/ Altiplano Plateau (Fig. 1). Multiple evidence indicates that these areas were continuously active over the last several glacial cycles.
Aeolian transport from Patagonia was often employed to explain the accumulation of the Pampean loess, the geochemical composition of sediment from the Southern Ocean and dust contained in Antarctic ice. However, chemical and isotopic fingerprinting methods has led to acceptance that Patagonian sediments can explain only part but not the entire range of compositions found in those archives. Other until now less considered but nevertheless important Southern Hemisphere regions

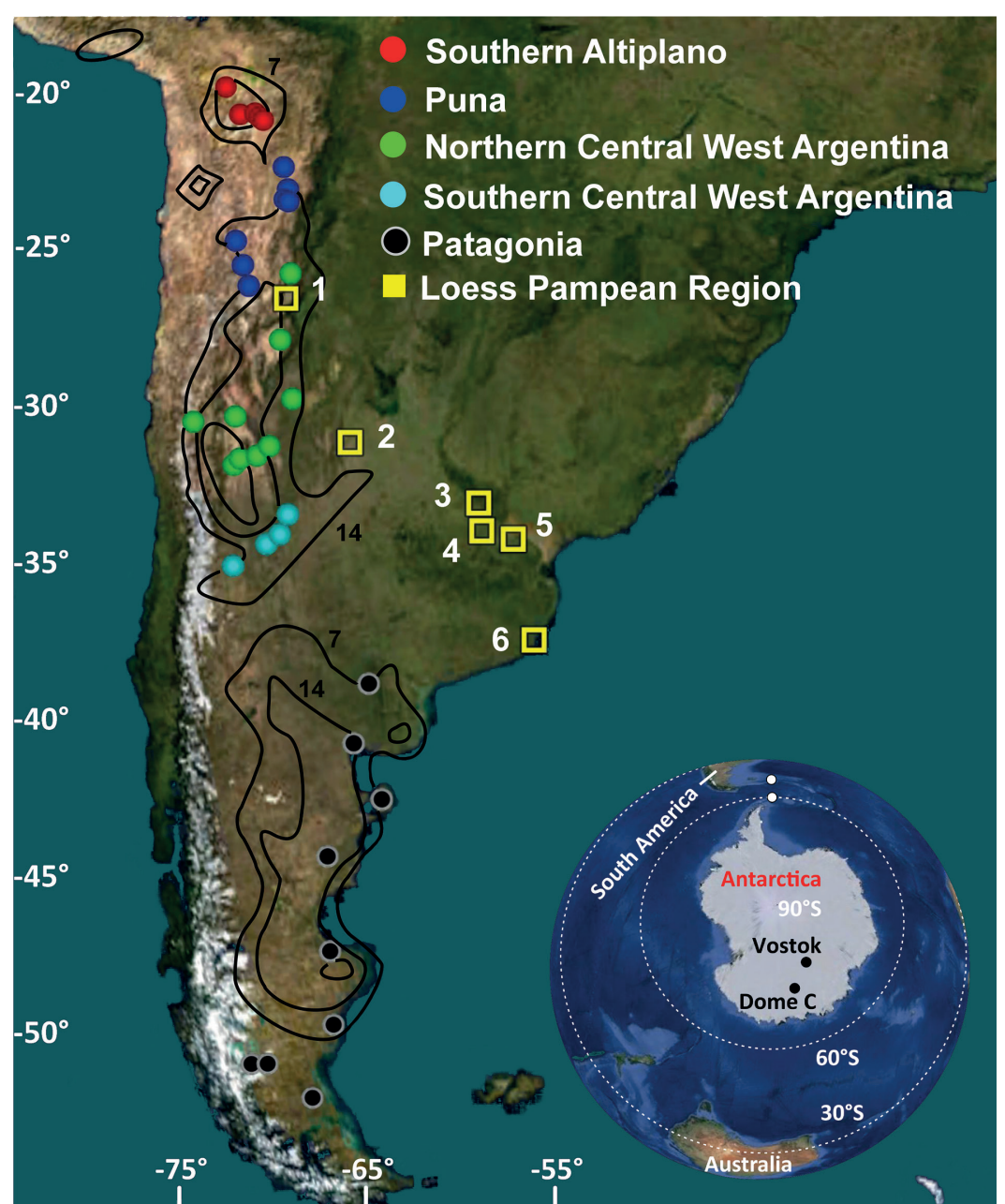

Figure 1: Location of the main present-day dust sources in southern South America (black lines show the number of days with dust activity during a year; adapted from Prospero et al. 2002). Color dots indicate the position of collected surface sediments used to define the rare earth elements signature regions as shown in Figure 2. Yellow squares show the position of proximal aeolian (loess) records across the Pampas (Smith et al. 2003; Gallet et al. 1998). Inset: Distal aeolian records. Scotia Sea (white dots; Diekmann et al. 2000), and Vostock and Epica Dome C (black dots; EPICA community members 2006). were also important suppliers of dust during glacial-interglacial cycles. Current international efforts are dedicated to better characterize these non-Patagonian dust sources (e.g. De Deckker, this issue). Here, we present new geochemical data of sediments from potential source areas (PSAs) in SSA north of Patagonia.

\section{Environmental setting of the PSAs}

A climatic transition at $\sim 38-39^{\circ} \mathrm{S}$ differentiates between regions dominated by summer rains to the north and winter rains to the south. South of this boundary lies Patagonia, a $\sim 700,000 \mathrm{~km}^{2}$ area of drylands that extend down to Tierra del Fuego $\left(\sim 54^{\circ} \mathrm{S}\right)$. The atmospheric circulation there is dominated by strong meridional pressure gradients that promote strong Westerlies and high wind speeds year round. The Westerlies are associated with cold frontal systems that are capable of lifting dust high into the atmosphere. During glacial times these fronts were probably even stronger than today.

North of $\sim 37^{\circ} \mathrm{S}$ the altitude of the Andes increases notably, disrupting the dominant zonal flow. East of the Andes lies the CWA region, a $\mathrm{N}-\mathrm{S}$ oriented strip of drylands $\left(36^{\circ}\right.$ to $\left.26^{\circ} \mathrm{S}\right)$ encompassing the geomorphological domains of the Andean piedmont and the western Pampean ranges. Meridional surface winds dominate present and quaternary atmospheric circulation over the north and central sectors of this area. In the south $\left(\sim 34^{\circ} \mathrm{S}\right.$ to $\left.38^{\circ} \mathrm{S}\right)$, SW winds prevail today and also dominated in the quaternary as reconstructed in loess and sand fields studied in the western Pampean region (Muhs and Zárate 2001). The area is cut by several ephemeral streams that form extensive sand flats, saline marshes, and saline lakes. The whole sector is drained to the south by the hydrographic system of the BermejoDesaguadero-Salado River $\left(\sim 250,000 \mathrm{~km}^{2}\right)$. A large volume of Andean sediments formed during the last glacial were transported by this hydrologic system to the south and then, once settled down, picked up by SW winds and transported to the northeast (Iriondo 1997).

The PAP area $\left(\sim 15^{\circ} \mathrm{S}\right.$ to $\left.26^{\circ} \mathrm{S}\right)$ is a high plateau ( $\sim, 000 \mathrm{~m}$ a.s. I). It consists of extensive, internally drained depocenters that contain large quantities of silt eroded from the surrounding $\mathrm{N}-\mathrm{S}$ oriented mountain ranges. The region is influenced by the subtropical jet stream, which intensifies during the austral winter and can 


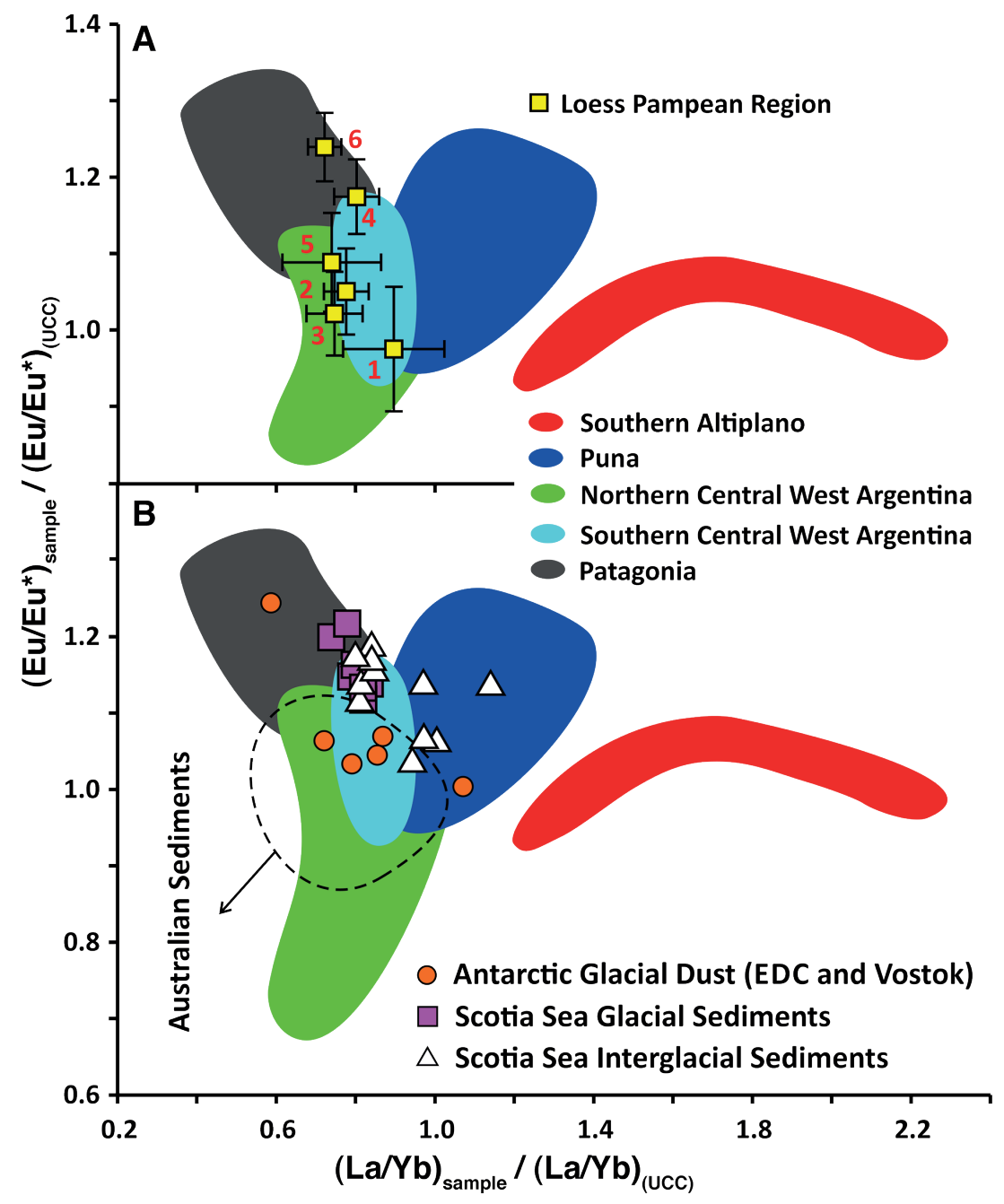

Figure 2: (A) Colored areas represent the rare earth elements (REEs) signature of the main potential dust sources in southern South America as inferred from surface sediments (Fig. 1). The yellow squares show the chemical composition of Pampean loess sequences (1, 2, 3, 5 and 6 from Smith et al. 2003; 4 from Gallet et al. 1998). (B) Comparison with distal geological records: sediments from the Scotia Sea and dust from East Antarctica (Basile et al. 1997; Diekmann et al. 2000). Autstralian sediments data from Gingele et al. 2007.

result in very strong winds that lead to sizable dust storms (Gaiero et al. 2013). Moreover most of the Altiplano was repeatedly covered with paleolakes during the Late Quaternary, indicating alternating cycles of dry and wet conditions. In the Puna, evidence indicates large depressions of primary aeolian origin of likely Pliocene and early Quaternary age. From about $18^{\circ} \mathrm{S}$ to $26^{\circ} \mathrm{S}$, sand dunes and windscoured ignimbrite ridges indicate a prevailing NW-SE wind direction during the late Pliocene and Pleistocene.

\section{Chemical fingerprint of the PSAs}

Figure 1a shows the locations where we collected surface sediment from arid and semiarid terrains (colored dots). Sampling locations were selected based on direct field evidence of dust activity and dust storms identified on satellite images. Sediment samples were taken from intermountain closed basins from a range of desiccated lake edges, fluvial-alluvial fans and enclosed basins.

Rare earth elements (REEs) analyses were run on $<63$ and $<5 \mu \mathrm{m}$ grain-size fractions of sediments. This group of elements is a very useful tool in sediment provenance studies because REEs inherit the composition of their sources. $\mathrm{La}_{\mathrm{N}} / \mathrm{Yb}_{\mathrm{N}}$ ratios and $\mathrm{Eu} / \mathrm{Eu}^{*}$ anomalies turned out to be particularly sensitive parameters for the recognition of PSAs. Based on these parameters it was possible to single out five PSAs (Fig. 2).

\section{SSA dust in geological archives}

The Pampean region is a large area $\left(\sim 10^{6} \mathrm{~km}^{2}\right)$ covered with a 20-50 m thick loess cover. It represents the proximal geological record of dust activity in SSA to the sources to the West. The chemical composition of loess sequences collected from sections 1-5 (Fig. 1), can be reconciled with the chemical composition of the non-Patagonian PSAs (Fig. 2A). The southernmost section (6) has a clear Patagonian signature, while the chemical fingerprint of the southern CWA prevails over the loess sections located further north (2, 3 and 5$)$. The provenance of aeolian materials in section $1(\sim 2,000$ $\mathrm{m}$ a.s.l) is contentious; for this area chemical data have the largest variability. From a mechanistic perspective, the Puna sector seems to be the most likely source because dust can be transported from there by upper tropospheric air masses. Unexpectedly, loess samples from section 4 are chemically different from samples from the nearby sections 3 and 5 .

The chemical signature of dust from SSA can also be recognized in distal geological archives. Figure 2B shows that the chemical composition of glacial-interglacial sediments deposited in the Scotia Sea, to the southeast of SSA, match well with the Patagonian signature and, to a lesser extent, with materials derived from the southern CWA. Notably, an important number of interglacial samples from the Scotia Sea fall within the compositional area corresponding to Puna surface sediments. The interpretation of the source of dust deposited in East Antarctica is more ambiguous as the chemical composition of four of the six samples also match the chemical composition of some surface sediments from Australia.

\section{Implications for further research}

The sediments from the PSAs of SSA have relatively distinct REE chemical compositions, which is a good prerequisite for a reliable paleo-climatic interpretation of the dust records of the SH. Our new data set from surface sediments suggests that most of the continental sediments deposited during glacial-interglacial periods in the Scotia Sea and the Pampas have REE comprised mostly of a mix of Patagonian, southern CWA and Puna origin. Contrary to other evidence, chemical data sug gest that southern Altiplano sediments play a minor role in the composition of these materials. The provenance of dust in East Antarctica is ambiguous, because the chemical REE composition is similar to Australian sediments as well as some of the PSAs in SSA. Therefore, other methods are required to unambiguously attribute East Antarctic dust to a provenance.

The possibility of distinguishing all these signatures in paleo-dust archives could be important to improving our understanding of the major atmospheric circulation patterns during the last glacial-interglacial cycles, such as understanding the equatorward and poleward displacements of the Westerlies and the subtropical westerly jet stream during the past climatic cycle. To achieve this, higher temporal resolution studies with appropriate age controls of Pampean loess sequences are required. Moreover and in addition to the REEs approach, more detailed analysis of the geochemistry (e.g. $\mathrm{Sr}, \mathrm{Nd}$, $\mathrm{Pb}$ isotopes) and mineralogy of surface sediments from SSA and Australia are needed.

\section{AFFILIATIONS}

Center for Earth Science Research, National University of Cordoba, Argentina

\section{CONTACT}

Stefania Gili: sgili@efn.uncor.edu

\section{REFERENCES}

Full reference list under:

www.pages-igbp.org/products/magazine/ref2014_2.pdf Diekmann B et al. (2000) Palaeogeogr Palaeoclimatol Palaeoecol 162: 357-387

Gaiero DM et al. (2013) J Geophys Res Atmos 118: 3817-3831

Iriondo M (1997) J S Am Earth Sci 10: 71-77

Muhs D, Zarate M (2001) In: Markgraf(Ed)

Interhemispheric Climate Linkages, Academic Press, 183-216

Smith J et al. (2003) Earth Planet Sci Lett 212: 181-196 